\title{
Soundings
}

\section{Feast or famine}

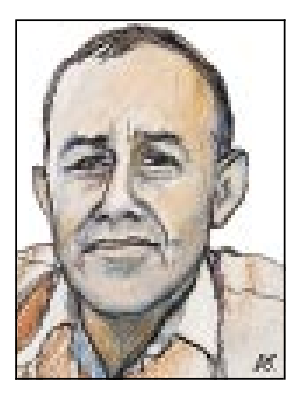

For more than a century various interested parties have been arguing over how many doctors we need, and whether we have too many or too few. Should there be a glut in desirable areas so there can be trickle down to less attractive ones? Should you regulate numbers or let market forces decide? Perceptions on these points have varied over the years, and so have official health policies, because in fact medical education in the United States is tightly regulated by professional licensing bodies and heavily subsidised by the government.

There seemed to be a shortage some 30 years ago. At the time even the rich often had to wait for weeks for a doctor's appointment. Whole counties without doctors would band together to recruit one. Private doctors shunned the poor areas of the inner city; and there was much talk about a crisis of access. Then the government encouraged the building of new medical schools and heavily subsidised medical education and training. Over the ensuing decades the number of US doctors increased, from 300000 to 684000 , amounting to 214 doctors per 100000 population, a higher ratio than in Canada (196) and Britain (164), but lower than in Italy (424), France (314), or Germany (256). At present some authorities estimate that by the year 2002 the US will have $20-30 \%$ more doctors than it needs.

Already signs of an abundance of doctors are apparent. Driving through Chicago you see many new medical facilities where once there were none. There are clinics run by health maintenance organisations and hospitals, emergency centres, day only surgicentres. There is no more talk about delays in getting to see a doctor, unless it is a well known specialist. Emergency rooms are fully staffed, hospitals have no trouble in recruiting doctors. Large rural towns have enough generalists and often boast a full complement of subspecialists. In most small towns the situation also seems to be under control.

Accordingly, young doctors no longer have it as easy as 20 years ago, when they could choose between competing practices and dictate their terms, some insisting on becoming full partners within one year. Now groups looking for new doctors are few, and many graduates hang around hospitals, work in emergency rooms, or join health maintenance organisations at comparatively low salaries. They go into full time positions or public health, a sure sign that the scales of supply and demand have tipped the other way.

As always, there remains a maldistribution between affluent and poor areas. But overall there is a perception of an impending glut of doctors and of a need to do something about it. Some officials have proposed cutting the influx of foreign doctors, a measure that would deprive less desirable and underserved urban and rural areas of needed services. Others want to close $10 \%$ of America's 125 medical schools, reduce student enrollment by $20-25 \%$, or cut back on resident training positions in hospitals.

Earlier this year the Clinton administration proposed redirecting some of the government’s $\$ 6 \mathrm{bn}$ ( $£ 3.8 \mathrm{bn}$ ) contribution to house staff training so that hospitals in New York could hire personnel other than residents. This was widely publicised as "paying hospitals not to train doctors" and compared with subsidising farmers not to grow crops. The debate is sure to continue, as will estimates of how many doctors are needed, underscoring the difficulties of central planning rather than relying on the dynamics of the market place, a pill that the medical establishment, health activists, liberal politicians, and government bureaucrats would find hard to swallow.

George Dunea, attending physician, Cook County Hospital, Chicago, USA

\section{Personal view}

\section{Genetic counselling-does the terminology matter?}

Counselling for bereavement, marriage guidance, post-traumatic stress, and psychosexual problems is all important to patients with particular needs. And stressed doctors are also making increasing use of counselling services. But for those wishing to reap the benefits of new genetic knowledge the term counselling may be sending the wrong message. Consultation should be used to describe the complete process that follows the recognition that a clinical genetic problem may exist.
The genetic consultation includes making an accurate diagnosis and risk computation, and requires elements of a standard medical consultation, including taking a family history, examining the patient, and interpreting genetic laboratory results. Genetic counselling, a component of the genetic consultation process, involves imparting accurate, sensitive, and complex information to the patient and family in a non-directive and empathic way, but after the diagnosis has been confirmed and risks estimated.
Soon all medical disciplines will need enhanced genetic awareness in their consultations as the human genome programme identifies an increasing number of genetic risk factors, including those for common diseases. Treatments linked to mutation analysis will split diseases presently lumped together-for example, hypertension, currently treated with a range of blunderbuss pharmaceuticals-and will drive forward new and more precise classifications and treatments for many generic diseases. Much 
research in cancer genetics is being targeted at this area. The major interest and investment of pharmaceutical companies suggest that they at least believe these breakthroughs are imminent.

The impact on general medical care will be substantial. Patients will come to expect prescribing to relate to their genetic profile and for it to be subsumed into best practice. The genetic consultation will be seen as an integral part of the medical interaction, an alarming prospect perhaps for the currently unprepared hospital specialist and general practitioner. The relative luxury of the extended genetic counselling session as practised in genetic centres must mutate into a new genetic consultation learnt by students in the revitalised curriculum in medical schools and capable of wide application.

The challenge for clinical geneticists will be to combine education of the health professionals to include the principles of patient autonomy, informed choice, and confidentiality. Chip technology will allow multiple mutation analysis on the surgery desk, but preparing the medical workforce for the new genetics requires equal investment.

Much of this depends on preserving the strength of general practice, which lies in its system of registration and lifetime records. But retrospective analyses of these records show ad hoc record keeping and information gaps with little evidence of family

\section{"Genetics will be too all pervasive...for it to be an optional extra."}

history data. There will need to be a commitment to information technology to process individual genetic data, to link genetic risk factors within families, and to access genetic helplines and current referral protocols. Consultation rates in general practice varying between four and seven a year give many opportunities to reinforce this genetic information.

Genetic registers, traditionally the province of departments of medical genetics, already exist in embryonic form in primary care. A personal survey of a group of Medi- tel users-the computer system used by almost one third of GPs-showed that $90 \%$ recorded and could report on patients with Mendelian conditions-cystic fibrosis, Huntington's, thalassaemia - as well as a range of common diseases with genetic predispositions-familial cancers, insulin dependent and non-insulin dependent diabetes mellitus, and Alzheimer's disease. The power of this information must be harnessed to increase patients' awareness of their genetic inheritance so that the genetic consultation becomes the gold standard of care in the next millennium. Without this there will be increasing litigation for genetic misinformation.

Genetics will be too all pervasive in medical care for it to be an optional extra for general practice and other specialties, and too ethically charged to attract item of service payments. It should be possible to retain the excellent model of genetic counselling while broadening its focus of activity to include it within a new terminology-the genetic consultation-for the benefit of patients and doctors.

Hilary J Harris, general practitioner, Manchester

\section{Medicine and the media}

\section{More openness needed in palliative care}

Annie Lindsell's request for a peaceful end to her life has filled many inches of newsprint in the last few weeks. Jessica Corner asks why there is still an element of fudge surrounding such cases.

Annie Lindsell, dying of motor neurone disease, this week withdrew her case at the High Court before any ruling was made, because her general practitioner agreed to her request for diamorphine. The papers subsequently declared a victory for Lindsell.

The Sun's headline "I won right to die," however, is not reflected in the reporting of her case. Lindsell, we read, "wanted the peace of knowing I could have an injection and that would be the end." Instead, her general practitioner expects to give her $5 \mathrm{mg}$ of diamorphine every 4-6 hours to relieve her suffering and distress, and also expects death to ensue over a matter of days. Both may be unlikely with this regimen.

Thus, euthanasia was requested but, instead, relief of suffering and early demise have been promised under the guise of "double effect"-the doctrine whereby doctors may legally administer potentially lethal doses of drugs as long as the intention is to relieve pain or distress. The reality is that the latitude normally afforded by the principle of double effect may have become much constrained by public declarations of the specific use of drugs and their doses. Meanwhile, the attorney general, who has, we are told, taken a close interest in the case, is no doubt breathing a sigh of relief since a judicial ruling and its ramifications have been avoided.
Melanie Philips in the Observer raises the concern that in our desperation to avoid using the term euthanasia in relation to actions and decisions surrounding the end of life, "the debate is becoming ever more muddled." One can only agree that the situation seems unsustainable when, in a single week, the Royal College of Paediatrics and Child Health concedes that it is ethically permissible to allow a seriously ill child's life to end, rather than prolong it artificially, while a mother is convicted of the manslaughter of her grossly handicapped daughter after removing a feeding tube (although given a suspended sentence).

The world of palliative care has tended to make a unilateral response to these cases, as in the recent expressions of outrage at the portrayal of a cancer victim suffocated in Channel 4's soap opera Brookside because the family felt they had no other means of relieving her suffering. An unsophisticated and alarmist portrayal by the Brookside team it may be, but palliative care's response, that such actions are no longer necessary since pain and suffering can be relieved with good palliation, is equally unhelpful.

The easing of death, as an intentional double effect is commonplace in palliative care and general practice, as revealed by Pulse magazine's recent survey of general practitioners. The "unclear and opaque" nature of law (Lord Lester in the Evening Standard) means that few doctors are prepared to make open declarations about their practice. This means that no formal guidelines exist as to the management of situations in which the doctrine of double effect might operate or the circumstances where these should be used. More worrying are issues such as gaining informed consent for a potential secondary effect and, when the patient is not competent to give consent, whether relatives should act as proxies.

At a time when all clinical decisions are to be made in the light of research evidence, maintaining a climate of fear and secrecy and somewhat paradoxically shrouding practice with grey ethical principles, is counterproductive. Palliative care needs to take the lead by making clear the strategies it employs for managing difficult situations at the end of life and, when double effect is used with the view that death is a likely and welcome secondary consequence, to be open about this.

Jessica Corner, director and deputy dean (nursing),

Centre for Cancer and Palliative Care Studies, Institute of Cancer Research/Royal Marsden NHS Trust, London 